\title{
Personal Identity Development in Cultural Context: The Socialization of Master Narratives about the Gendered Life Course
}

\author{
Kate C. McLean ${ }^{1}$ \\ Samantha Boggs ${ }^{1}$ \\ Kristin Haraldsson ${ }^{1}$ \\ Alexandra Lowe ${ }^{1}$ \\ Chelsea Fordham ${ }^{1}$ \\ Staci Byers ${ }^{1}$ \\ Moin Syed ${ }^{2}$
}

\footnotetext{
${ }^{1}$ Western Washington University

${ }^{2}$ University of Minnesota
}

Author Note. We thank the narrative lab at Western Washington University for data collection, and coding, and Western Washington University and the Center for CrossCultural Research for funding. We thank Annie Riggs for comments on an earlier version of this manuscript.

Key words: narrative identity, gender identity, master narratives, cultural change, socialization 


\begin{abstract}
The present studies focused on the role and socialization of biographical master narratives cultural narratives that prescribe the types and ordering of events that should occur in one's personal life identity narrative - by focusing on adolescent and emerging adult gender identity development. We employed a combined explanatory and triangulation mixed methods design. Study 1a $(n=414)$ was a survey study examining the expected biographical master narrative events for men and women, and the content of master narrative deviation and conformity in an emerging adult sample. In Study $1 \mathrm{~b}(n=14)$ we interviewed participants from Study 1a about their conformity and deviation narratives, as well as their socialization experiences regarding gendered biographical master narratives. In Study 2 mothers and adolescents ( $n=11$ pairs), engaged in conversation about expected life course events, as well as a follow-up interview about their conversation. We first found that there are more gender differences in the personal experiences of conformity to and deviation from master narratives compared to the expectations of the life course (Study 1a). Second, deviating is related to more engagement in identity processes (Study 1a). Third, emerging adults report contradictions in retrospective reports of socialization messages regarding expectations (Study 1b), a finding confirmed in a discourse analysis of mothers and their adolescents (Study 2). Overall, across the studies, we see that 1) adolescents and emerging adults are engaged in a delicate balance of negotiating between various cultural and familial messages, as well as personal experiences, about gender identity particularly in regards to gender equality and, 2) there is a complex relation between socialization messages about gender equality that may make some biographical master narratives about the expected life course events for men and women more resistant to change.
\end{abstract} Key words: narrative identity, gender identity, master narratives, cultural change, socialization 


\section{Personal Identity Development in Cultural Context: The Socialization of Master Narratives about the Gendered Life Course}

Theoretical approaches to identity development emphasize the necessity of attending to both intrapsychic processes as well as the cultural contexts in which identities are developing and negotiated (e.g., Erikson, 1968). That is, the ways in which adolescents and emerging adults come to understand who they are involve understanding how they are located within their cultural context. We employed a relatively recent framework designed to address these dynamics focusing on the negotiation of personal and master narratives (McLean \& Syed, 2015). In particular, a biographical master narrative prescribes the types and ordering of events that should be present in one's personal identity narrative (McLean \& Syed, 2015; see also Arnett, 2017; Habermas, 2007; Rubin \& Berntsen, 2003), and individuals must negotiate their personal narratives within these cultural expectations. We build on this framework, introducing a novel examination of the ways in which master narratives are socialized, focusing on the domain of gender, and employing a perspective that seeks to 'reimagine' development, not as stemming

from the relatively passive process of socializing dominant cultural messages, but as the dynamic and active engagement of individuals accommodating and resisting those messages (Rogers \& Way, 2018).

\section{A Cultural Framework for the Study of Identity Development}

Erikson (1968) argued that the task of identity development initiates with a questioning of the identifications adopted in childhood, facilitated by growing cognitive abilities to wrestle with complexity and paradox, and the growing press from others to know who one is. The task of the individual is to find a way to integrate the various components of identity - across both 
time and context - as well as to find an integration between oneself and the larger cultural context - the self and society (Erikson, 1968; Syed \& McLean, 2016).

A recent framework to capture the link between self and society gives prominence to group differences in the use of and allegiance to these expectations: the master narrative framework (McLean \& Syed, 2015; see also Hammack, 2008). Master narratives serve as templates for the kinds of experiences one should be having, and how to interpret them - i.e., templates for a culturally normative, valued biography. This framework is bi-directional: as individuals negotiate with these narratives in developing their own identities, they are engaging in a process that can serve to maintain or to change them.

There is a long history in developmental psychology of approaches that emphasize how individuals align with or deviate from socio-cultural expectations (e.g., Heckhausen, Wrosch, \& Fleeson, 2001; Helson, Mitchell, \& Moane, 1984; Neugarten, Moore, \& Lowe, 1965). Master narratives differ from these approaches because they serve not only as scaffolds for personal identity development, they also serve to maintain hierarchies of power and privilege. For example, the traditional master narrative of gender reifies women's position as caregivers, which includes being in positions of lesser economic power. Thus, the master narrative framework centers on issues of power and privilege in terms of who aligns and deviates, how deviation can impinge on identity development, and the ways that master narratives are maintained and changed via processes of identity development. This framework is consistent with Rogers and Way's (2018) recent claim that the unfolding of development itself is situated in processes in which individuals can both accommodate and resist master narratives as part of their own identity processes. 


\section{The Relation between Identity Development and Master Narrative Negotiation: Rigidity and Change}

When individuals align with master narratives, such as when a woman views her caregiving role as central to her identity, we see an identity process that maintains them. In contrast, when individuals resist a master narrative, such as when a man views caregiving as central to his identity, the possibility of changing master narratives emerges as individuals begin to craft alternative narratives. Alternative narratives are constructed in contrast to master narratives, providing an alternative pathway for self-definition. Although the possibility for master narrative change exists, because cultures require some stability in their foundations, a central piece of the framework is the rigidity of master narratives.

The framework suggests that one mechanism of change and rigidity comes through personal identity development processes, with greater identity work particularly important for processes of change. For example, those who are engaged with alternative narratives are also engaged with more identity work (McLean, Lilgendahl, Fordham, Alpert, Marsden, \& Szymanowski, \& McAdams, 2017a; McLean, Shucard, \& Syed, 2017b). Another obvious developmental mechanism of change and rigidity is socialization, which has not yet been empirically addressed within the master narrative framework. In this initial exploration we examine a domain of identity rich with socialization processes: gender.

Gender Identity: Negotiating and Socializing Traditional and Equality Master Narratives

The master narrative framework is easily applied to an examination of gender, a salient component of self and identity across development (Egan \& Perry, 2001; Fivush \& Buckner, 2003; Gelman, Taylor, Nguyen, \& Leaper, 2004; McLean et al., 2017b; Rogers \& Meltzoff, 2017; Ruble, Martin, \& Berenbaum, 2006), because gender is a hierarchical social category in 
which men are viewed as superior to women (e.g., Gilligan, 1982; Risman, 2004; Rogers \& Way, 2018). Further, the American cultural context (in which this study was based) has undergone shifts in the location of gender in regard to notions of equality, but those shifts are slow-moving and gender inequality has proven persistent, making an examination of rigidity and change relatively visible in this domain.

In our initial work we found that emerging adults negotiated their personal identities in reference to traditional gender expectations, which maintain systems of inequality, and newer expectations that emphasize gender equality, or traditional and equality biographical master narratives (McLean et al., 2017b). The traditional narrative dictates a gendered division of expected experiences and the meaning of those experiences (e.g., caregiving), and the equality narrative de-emphasizes gender differences with a message of opportunity for all. Importantly, men are more likely to align with the former, and women with the latter (McLean et al., 2017b).

What we do not know is how these identity negotiations are related to messages from socialization agents. In fact, we know relatively little about gender socialization after childhood. Further, although developmental psychology is founded on traditions that emphasize the transmission of cultural messages as central to processes of development (e.g., Bronfenbrenner, 1979), there has been less attention to dynamic negotiations, particularly how recipients play a role in reproducing these messages (i.e., mechanisms of stability) (Hammack, 2008), or mechanisms by which socialization does not lead to the internalization and reification of these messages (i.e., change) (Rogers \& Way, 2018). For example, the reliable association between parents' attitudes about gender and children's gender schemas (see Tenenbaum \& Leaper, 2002) has often been interpreted as evidence that transmission of cultural messages flows from parents to children. One mechanism for this transmission is conversations, in which parents can both 
implicitly and explicitly communicate messages (e.g., Gelman et al., 2004; see also Zaman \& Fivush, 2011). However, analysis of conversations also allows an investigation of how the 'recipients' align with or resist these messages. This framework of a bi-directional and dynamic process of negotiation between master narratives and personal identity was the foundation of the present studies.

\section{Present Studies}

We adopted a combined explanatory and triangulation mixed methods design to address how adolescents and emerging adults align with or deviate from narrativized cultural expectations about gender, how parents message these narratives, how their children negotiate with those messages, and how these negotiations reveal cultural movement or rigidity. Given our interest in the role of dominant and hierarchical messages about gender, this investigation was done within a heteronormative, cisgender framework; that is, we examined how the negotiation of gender identity is done in reference to these traditional expectations that maintain systemic inequalities (see also Rogers \& Way, 2018).

Our first study (Study 1a) set the quantitative foundation (per an explanatory mixedmethods design) by defining the content of the gendered biographical narrative, examining gender differences in conformity and deviation, and relations with identity processes. We asked whether participants had conformed to or deviated from master narratives, and then coded the content of their responses to understand what the narratives actually are (i.e., the culturally expected events). Deviation narratives are particularly useful for understanding the content of master narratives because they are most visible when they are not followed (McLean \& Syed, 2015). Following the logic of an explanatory mixed methods design, Study $1 \mathrm{~b}$ featured a qualitative analysis to elucidate processes of conformity, deviation, and socialization. For 
Studies $1 \mathrm{a}$ and $1 \mathrm{~b}$, we targeted emerging adults $(18-29)$, representing a developmental stage when decisions about certain life events become more salient and tangible. The triangulation aspect of the mixed methods design sought to investigate if the findings from Study $1 \mathrm{a}$ and $1 \mathrm{~b}$ would be consistent in a different age group (mothers and adolescent children) and different method (conversations). We were guided by three research questions:

RQ1: What is the gendered master narrative for men and women, and are there gender differences in conformity and deviation (Study 1a)? We examined 1) the types of events reported as important for occurring in the life course of a typical man or women, 2) the importance of particular life events, and 3) personal experiences of conformity and deviation. We expected that men would report greater conformity to the traditional narrative and women would report greater conformity to the equality narrative (McLean et al., 2017b).

\section{RQ2: Are narrative patterns in the deviations related to identity development}

processes (Study 1a)? We expected that those who deviated and elaborated an alternative narrative would report greater identity development processes (McLean et al., 2017a; 2017b), specifically - making more explicit narrative connections between an event and the self, and higher scores on identity exploration.

RQ3: How are master narratives negotiated and socialized? We addressed this through interviews about retrospective reports of perceptions of socialization experiences (Study 1b), and observations of mother-adolescent conversations (Study 2). We discuss the theoretical background for this question in introducing these studies.

\section{Study 1a: Methods}

\section{Participants}


Participants were 414 emerging adults: 285 undergraduate and 54 graduate students from a state university, and 75 students from a community college, all in the Pacific Northwest. Participants were predominantly heterosexual (82\%) and White (76\%) (see Table 1).

\section{Procedure}

University undergraduates were recruited through subject pool courses that satisfy general education requirements for a variety of majors, and received course credit for participation. Graduate students (from a wide variety of programs) were recruited via email, and were paid $\$ 10$ for participation. Both groups completed the study on computers in a room alone. Community college students were recruited by their professors and members of the research team in introductory-level psychology courses, completing the survey during class or online, receiving extra course credit for participation.

\section{Materials}

The following prompts are described in the order completed, which were followed by survey assessments. Full narrative prompts and assessments not included in the present analysis are available on [OSF page].

Biographical Master Narrative. Modeled after Bernsten and Rubin's (2004) life script task, this prompt was designed to capture the American biographical narrative for men and women. Participants were instructed to report the most important events (and their order) that should occur in the typical life of someone of their gender, with instructions including:

Your task is to decide which events are expected to take place in the typical life course for a male/female in this culture...Imagine a quite ordinary male/female. It cannot be a specific person that you know, but a prototypical person with a typical life course ahead. Your task is to write down the most important events that you imagine will occur during this person's life. 
Master Narrative Conformity or Deviation. Participants were asked if they had deviated from the master narrative for their gender (e.g., McLean et al., 2017a), with the following description: "Sometimes stories from our lives, or aspects of our lives, do not completely match the storyline that others (society, culture, family, friends, etc.) expect us to have, or what is considered appropriate, normal, or accepted." They were then asked if they had ever felt that, and depending on that answer, they were asked to describe a memorable event regarding the deviation, or to elaborate on why they had not deviated.

Event Ratings. Participants used a 5-point scale to rate the importance of experiencing a set of 14 life events for a person of their gender, based on Bernsten and Rubin's (2004) findings regarding the most frequently reported expected life course events (see Table 3).

Ego Identity Process Questionnaire (EIPQ; Balisteri, Busch-Rossnagel, \& Geisinger, 1995). This 32-item scale assessed individuals' identity commitment and exploration, using a seven-point Likert scale (overall identity exploration, Cronbach's $\alpha=.80)^{1}$.

\section{Narrative coding}

All narratives were coded by one of the authors as part of her MS thesis project (coding manuals and sample narratives are available on [OSF page]). Research assistants were trained and then coded a subset of narratives (15-30\%, depending on the system and base rates) to establish reliability with this author. We report percent agreement along with kappas because some categories have low base rates. After reaching reliability, the same research assistants coded subsequent subsets of the narratives to check for coder drift; disagreements were settled by consensus (Syed \& Nelson, 2015).

\footnotetext{
${ }^{1}$ Participants who did not complete at least $75 \%$ of the items were excluded, resulting in some in sample size difference. Those who completed more than $75 \%$ had missing data points substituted for their scale average.
} 
Biographical Master Narrative Content. In responding to the biographical master narrative prompt, participants reported quite a variety of events. To narrow the scope to a manageable set of codes, and to be consistent with other measures in this study, we coded responses to the deviation prompt for the presence or absence for those events that researchers have already established as culturally expected (Bernsten \& Rubin, 2004) (see reliability in Table 4).

\section{Conformity or Deviation Content}

The coding team began by multiple and extensive readings of the narratives responding to the deviation prompt to capture the most common categories and define the rules for inclusion or exclusion in each mutually exclusive category (see Table 4 for reliabilities). To code for conformity or deviation, coders needed to know participant gender (e.g., acting in a feminine way would be conformity for women, and deviation for men).

Conformity. Traditional master narrative conformity was represented by alignment with gendered expectations (e.g., a man providing financially for his family). Equality narrative conformity was defined by the assumption of gender equality (e.g., no one is limited by their gender). Non-specific conformity narratives do not address gender (e.g., describing oneself as normal). Other describes narratives in which other types of deviation are discussed not related to gender (e.g., being a person of color in a majority-White location).

Deviation. Norms captures deviations from cultural expectations for masculinity/femininity (e.g., interests). Sexuality or sexual behaviors describes deviations from heteronormativity (e.g., being a promiscuous woman). Gender beliefs describes beliefs or attitudes that contradict cultural expectations (e.g., identifying as a feminist in a conservative location). Gendered life course events pertain to specific events related to gender (e.g., 
childbearing). Timing or Omission describes deviations where typical events are out of order, but not gendered (e.g., being an older college student). Unexpected events occur outside the typical life course and are not gendered (e.g., addiction).

\section{Identity Processes}

Development of Alternative Narrative. This 4-point scale was only applied to those who reported that they deviated, and represented the degree to which an alternative narrative was elaborated within a personal narrative (McLean et al., 2017a). Coders also considered the agency expressed within the narrative, with higher scores representing greater elaboration and agency $(I C C=.91)$. This is consistent with recent work showing that the fullest form of alternative narrative engagement involves elaboration (one must be able to elaborate a narrative in order for it to contribute to identity), and encompasses some sense of felt agency or empowerment (McLean et al., 2017; see also Toolis \& Hammack, 2015).

Self-event Connections. Narratives were coded for the presence or absence of explicit connections between the event and the narrator's self (e.g., traits; kappa $=.79$ ) (Pasupathi, Brubaker, \& Mansour, 2007). Few participants reported more than one connection, so this was a binary variable (presence/absence).

\section{Study 1a: Results}

Means, standard deviations, and frequencies for all variables are listed in Table 1 (see [OSF page] for age and sample differences). We used adjusted standardized residuals (ASRs) for chi-square analyses, which serve as a standardized measurement of the discrepancy between expected and observed values for individual cells, and are similar to a z-score (i.e., an ASR > 1 is meaningful). We also report Cramer's v, an effect size index that represents the strength of the association between two variables. Note that sample size differs as not all codes were applied to 
all participants (e.g., alternative narrative development could only be coded for those who deviated). Results are reported without controlling for word count, which did not alter results. RQ1: What is the gendered master narrative for men and women, and are there gender differences in prevalence, important, and conformity/deviation?

There were few gender differences in the prevalence of life course events reported as normative (see Table 2), with the largest gender difference for devoting energy to childrearing. In terms of importance of these events, we used a Bonferroni correction (overall $\alpha=.05$ ) to control for the increased statistical error in conducting fourteen repeated t-tests $($ critical $p$-value $=$ .003). Two events showed gender differences (Table 3): men rated choosing a career and devoting energy to career advancement as more important than women.

In terms of personal experiences, there were gender differences for conformity, $X^{2}(18, N$ $=381)=41.99, p=.001, \mathrm{v}=.24($ see Table 4$)$, with women over-represented in conforming to an equality narrative, and men over-represented in conformity to a traditional narrative. In terms of deviation, men were overrepresented in deviations regarding norms of masculinity and femininity, and sexuality. Women were overrepresented in reporting deviations regarding gendered life events (e.g., childbearing).

\section{RQ2: Are narrative patterns in the deviations related to identity development?}

There were no gender differences in alternative narrative development, $t(378)=-1.44, p$ $=.15$, or identity exploration, $t(394)=-1.22, p=.22$. However, men's deviation narratives were marginally more likely to contain a self-event connection than women's, $X^{2}(2, N=381)=6.17$, $p=.05, \mathrm{v}=.09$. As predicted, alternative narrative development was associated with identity exploration, $r(375)=.26, p=.001$. Further, the presence of self-event connections was 
associated with more developed alternative narratives $(M=3.19 ; S D=.70)$ compared to the absence of connections $(M=2.38 ; S D=1.08), t(384)=-6.08, p=.001, d=.88$.

\section{Brief Discussion and Introduction to Study 1b}

Our aim was to define the content of the gendered biographical narrative, and to examine the role of gender and identity processes in conformity and deviation. In terms of the expectations for life course events, we saw gender differences for three events: choosing a career, and devoting energy to career advancement, and to childrearing (Table 2). This is consistent with a traditional master narrative, as well as the normative division of labor in American households (Lindsey, 2015; Meeussen, Veldman, \& Van Laar, 2016). In terms of personal experiences, men were more likely to align with a traditional master narrative, and women were more likely to align with an equality narrative. In terms of deviations, men were more likely to focus on personal characteristics (e.g., norms of femininity and masculinity), while women were more likely to focus on life events (e.g., childrearing) (see Table 4), suggesting that the concept of biographical events may be more relevant to women's identities than to men's. These findings suggest that while the expected life course events are generally similar, greater differences lie in participant's actual experiences. This may mean that the ideals of gender equality hover above the realities of lived experience, posing some challenge for identity development, a paradox we surfaced in Studies $1 \mathrm{~b}$ and 2.

Although we identified gender differences in deviations and conformity, there are likely more dynamics in negotiating the tension between these two narratives. Indeed, Rogers and Way (2018) emphasized how conformity and resistance can occur simultaneously. In contrast to survey measures, the processes of narrative negotiation are more vividly observed in discourse where people can dynamically position themselves towards, against, and between various 
narratives (Korobov \& Bamberg, 2004). We were particularly motivated to explore this positioning in recollections of socialization in relation to personal identity work and to the rigidity and change of master narratives.

\section{Study 1b: Methods}

\section{Procedure}

Participants were recruited from Study la via email with an opportunity to participate in a follow-up study (all contacted agreed to participate; $n=14$ ). To capture a range of all of the narrative content reported in Study 1a, we recruited 4 participants who represented conformity: traditional $(n=2)$ and equality $(n=2)$; the remaining represented deviation: gendered life events $(n=2)$, norms of masculinity and femininity $(n=4)$, sexuality/sexual behaviors $(n=1)$, beliefs about gender $(n=3)$. Participants completed an audio-recorded interview, and were compensated $\$ 15$.

\section{Participants}

Ages ranged from 18 to 27 (mean $=21.8)$. Eight participants identified as female; 12 as White, one as Asian, one as mixed: 11 identified as heterosexual, two as bisexual, one as homosexual.

\section{Interview}

The interview began by asking similar questions to Study 1 about gendered expectations for the life course, followed by questions about 1) parental socialization, 2) peer socialization, and 3) thoughts on gender discrimination. Participants were then presented with their deviation narrative from Study 1a and were asked to elaborate on how it related to their identity. The interview concluded with questions about how participants thought their experiences might impact future decisions (e.g., regarding romance or career). 


\section{Analytic Process}

Our analytic framework was guided by consensus rather than formal reliability, given the small sample size and intention to conduct an interpretive, in-depth analysis (Syed \& Nelson, 2015). The coding team consisted of a professor, graduate student, and several undergraduates. Members of the team read each interview transcript in depth and then discussed initial interpretations. We then divided the cases so that each member of the coding team profiled several cases with at least one overlap (i.e., at least two coders read each case). We then combined those analyses to create final profiles of each interview, which consisted of several paragraphs per participant describing how each participant's interview addressed study questions. Finally, we discussed each profile as a group to uncover broader themes related to socialization and positioning.

\section{Study 1b: Results and Discussion}

\section{Processes of Socialization in Relation to Conformity and Deviation}

Not surprisingly, most participants pointed to varied sources of information about life course expectations from messages communicated by family, peers, the media, faith communities and religious texts, as well as behavioral observations. We identified reports of socializing both traditional and equality narratives, perhaps reflecting the contemporary condition of cultural shift. Examples of traditional socialization included messages about what toys and chores are appropriate for boys and girls and how that relates to future career and life choices, and the importance of childrearing for women. Examples of socialization into the equality narrative included an emphasis on female independence and autonomy from men, particularly in relation to romance, as well as the idea that men and women have equal opportunity to pursue any life experiences that they want. 
Recollections of socialization regarding these two narratives were also related to processes of identity development. Some participants distanced themselves from mechanisms of socialization, not perceiving their experiences to be influenced by socio-cultural expectations. For example, one participant emphasized the role of biology in childrearing, suggesting that life choices were dictated by what individuals "gravitate towards," or "whoever gets the job done." This kind of sense-making removes cultural affordances and barriers (not to mention biological ones) from the conversation, and also removes need for reflective identity work since these differences are viewed as relatively natural or automatic. Such thinking also reinforces a traditional narrative in the language of an equality narrative, with the emphasis on an agentic 'choice.' This is consistent with the idea that those who conform to master narratives may do so without conscious awareness of the constraints such narratives impose on pathways of identity development (McLean \& Syed, 2015), and also provides a potential mechanism of maintaining master narratives.

For other participants, moments of socialization prompted identity work regarding deviations. One participant reflected on a teacher's expectations for children:

And so it made me really think, like..."what if I don't want kids? What if I don't want my own kids?"... It really just made me think about a bunch of different topics. So I thought to myself, who are you to tell me I should or shouldn't have kids, or assume that I'm automatically going to have kids.

This example reveals the constraints that the traditional narrative imposes regarding childbearing/rearing (a common theme across studies), and how deviation prompts reflective processes.

\section{Negotiating the Traditional and Equality Narrative}

The traditional and equality narratives were not always discussed in isolation (see Rogers \& Way, 2018), resulting in tension and confusion. Some participants reported that their parents' 
words and actions did not always align. For example, one participant reported that her father explicitly socialized equality, and implicitly socialized traditional expectations:

...has raised my sister and I kind of as, like trying to resist that system, even though in lot of ways, my dad plays into it... he felt like he needed to be protective of me more instead of teaching me to stand up for myself, you know? So he wasn't directly like, "You need to wear dresses and have long blonde hair and like do all these stereotypical things." It was almost like he didn't realize how he was engaging with me was furthering this idea that I needed to be protected and I couldn't speak for myself.

We saw this wrestling with divergent narratives not only in socialization messages, but also in individuals' reflections on their own lives. One participant reported a lengthy narrative in which she volleyed back and forth between traditional and equality expectations. She reported that her parents socialized her "away from female constructs" as a protective measure because a stereotypically feminine life course would bring the pain of inequality. Yet even though she is excelling in a male-dominated field, she thinks she will likely conform to a more traditional narrative, "I think that I'm still have like uh, female gender constructs. Like I do think that I'll grow up and get married and be in a relationship in that manner." It is possible that the confusion from the competing narratives, pushes individuals towards relying on the more familiar, and expected, traditional narrative - it may simply be easier to do so.

\section{Narrative Rigidity}

The socialization of both the traditional and equality narratives involves rigidity, or an emphasis on conformity (McLean et al., 2017b). This rigidity in the traditional master narrative is less surprising because it is established with historical weight. It is perhaps more surprising that the equality narrative comes with such rigidity because equality is associated with greater 'freedom.' However, this freedom may be at a surface level, as reported by one participant whose parents explicitly socialized equality: 
I do remember a couple of times my mom talking about the other moms who...didn't have jobs or worked at the home. And I remember my mom kind of making almost judgmental comments about them, but then kind of being like "oh well like that's their choice, but" in almost like a "I'm judging them, but I'm not judging them."

This discussion of denigration of those who follow the traditional pathway is followed by this participant's disclosure of her need to attend therapy, in part because her desire to be in a relationship contradicts her mother's messages about being "a strong independent woman...to the point where it did become bad to be feminine." The power of the equality narrative is on par with the power of the traditional narrative in terms of herding individuals into narrative expectations, which necessarily comes with constraint. We also note the use of the word "choice" here, as we did with the participant who emphasized the importance of natural inclinations. This mother positions herself within the equality narrative by suggesting that the traditional pathway is a choice, not a result of societal structures and expectations.

In sum, these interviews revealed the contradiction in socialization messages, which was associated with identity conflict as individuals wrestled with how and whether to internalize them. We also saw vivid examples of narrative rigidity. However, these data are compromised by their reconstructive nature, which prompted us to examine these socialization processes in vivo.

\section{Introduction to Study 2}

As part of the triangulation of our mixed-methods design our aim was to examine consistency in the themes we have observed in a different age group (mothers and adolescent children) and with a different method (conversations). Consistent with discursive approaches (e.g., Korobov \& Bamberg, 2004), examining conversational processes is a way to understand the construction of personal identity within a "shared cultural model of sense-making" (Bamberg, 2004, p. 334). Interpersonal interactions are also viewed as primary mechanisms of 
master narrative maintenance and change (e.g., McLean et al., 2017b; Thorne \& McLean, 2003). However, we also included a 'playback interview' to understand participants' reactions to and evaluations of the conversation, as well as to offer participants a chance to communicate thoughts or experiences not shared in the conversation.

\section{Study 2: Methods}

\section{Participants}

Participants were 11 mother-adolescent pairs (child mean age $=17.00$; mother age $=$ 44.27; 5 daughters, 6 sons). Seventeen participants reported their ethnicity as White/Caucasian, 1 as Latinx, and 4 as mixed. On a scale measure, sixteen participants reported being straight/heterosexual. One mother and three children ( 2 daughters, one son) reported being mostly straight, one daughter reported being bisexual, and one daughter reported being mostly gay/lesbian. Mothers reported that they were married $(n=7)$, divorced $(n=3)$, remarried $(n=$ 1). Yearly family income ranged from $30-40 \mathrm{k}(n=1), 40-50 \mathrm{k}(n=2), 90-100 \mathrm{k}(n=6)$, over 100k $(n=2)$. Four mothers worked part-time outside the home, and seven worked full-time outside the home. One mother reported 'some college,' two had a college degree, one had done 'some' graduate work, and seven had a graduate degree. English was the primary language spoken at home.

\section{Procedure}

Each participant completed the survey from Study 1a. They were then brought together to discuss their thoughts and experiences related to the survey for 15 minutes (conversation prompt available on [OSF page]); this was video- and audio-recorded. Each participant was then taken to a separate room for a play-back interview. The conversation audio was re-played, and participants were instructed to stop the recording at any time to comment on or explain 
something happening in the conversation, particularly if there was something unsaid. Research assistants could also stop the tape if they needed clarification or had questions. Participants were then asked about how much they discussed issues of gender with their child/parent, and their thoughts about division of labor and gender discrimination. The playback interview provides a very different way of eliciting information, as individuals may feel more open to reveal themselves to a researcher than an intimate, particularly concerning points of disagreement. Further, participants have the chance to actually think about what they said and why, which is very different from conversational data. The comments and interview were audio-recorded and transcribed. Each participant was compensated \$20.

\section{Analytic Process}

Our framework was the same as in Study 1b (see also McLean et al., 2017b), and some members of the same team engaged in these analyses. Coders read each survey, conversation and playback transcript in depth, followed by a group discussion of each dyad. As themes emerged, they were recorded and elaborated with the review of each subsequent case. Next, the entire corpus was re-reviewed to determine commonalities and distinctions, with a focus on processes of socialization and points of paradox related to master narrative negotiation.

\section{Study 2: Results and Discussion}

We organize our results around the socialization of the equality narrative, as that emerged in all conversations, but in different ways, largely related to its visibility or invisibility. We do note, however where the traditional narrative emerged, as it is hard to discuss one without the other.

\section{The Invisibility of the Equality Narrative}


A common theme in the playback interviews (mostly with mothers) was the assumption of the equality narrative, which negated the need for explicit discussion. For example, two mothers reported the following in their playback interviews:

I don't know that we specifically talk about those sorts of things. Like I've said, we discussed a lot. But the absolute topic of doing the same types of things... (pause) I'm not sure that we've ever really talked about it in that aspect. Does that make sense? (Laughs) Um, I don't see why they can't do the same things. I don't know. That's a hard question to answer for some reason.

I don't think we talk about it outright. I think it's just assumed that he would know that. So that's interesting. I don't actually_-I've not confirmed if that that's what he believes, but I guess I've always assumed that um, he would think males and females could do the same thing...

In a follow-up response, the second mother says issues of inequality come up "in passing." But that before the recent (2016) American presidential race, “...gender equity never entered our conversation." Her son confirms this in his playback interview, "We don't really discuss it...that much."

One way to interpret this lack of discussion is that addressing inequality would challenge the equality narrative - they cannot both exist as they are in direct contrast. Yet sometimes mothers engaged in explicitly contradictory behavior (as we saw reported in Study 1b). For example, one mother acknowledged barriers to equality, but stated that she socializes her child to do what she wants "...regardless of her gender and if it's male dominated or not." This is a particularly interesting tactic because there is acknowledgement of structural inequalities, but without preparation for facing them (cf., racial socialization processes; Hughes \& Johnson, 2001).

\section{Visibility of Equality Narrative}

In contrast, some mothers were clear about their explicit socialization of gender equality and, for some, that such socialization was central to their identities. In one conversation, a 
mother and daughter agree that gender is a common topic of conversation, and the mother relays specific conversational examples, including intergenerational stories, and stories about nontraditional gender roles in the home. These socialization efforts appear to have paid off for this mother in validating her identity. For example, at the beginning of the conversation, this mother states that she had a hard time rating the importance of romantic commitment to the life course, given her value on independence for women. Reminiscent of the interviewee in Study $1 \mathrm{~b}$ who discussed the socialization against being in relationships, this woman's daughter then said, “It's [romantic commitment] not important at all...like it's nice, but it's not like crucial for my life, you know?" The mother responds, "I just want you to know that I feel like that validates the entire way that I mothered you."

But it appears that things might not be quite so clear. Despite this conversational agreement about the emphasis on the equality narrative, the daughter expresses confusion in her interview about what her mother actually thinks, and she says they haven't talked about it: “Usually there's kind of, uhm, conversations that skew towards that there's usually one or two comments before it's kind of ended because it is an uncomfortable subject because we don't agree on everything." What to make of the contradiction between interview and conversational data?

First, the mother's socialization may be more complicated than we think. She puts a lot of emphasis on not following others' expectations. However, she has clear expectations, some of which are reflective of the traditional narrative, contradicting earlier statements. When she said her daughter's de-valuing of romance validated her own identity, the daughter responds:

C: Says the one who's like "when are you going to get married?", "When are you going to have kids?"

M: I never- no I said when are you going to give me grandkids...

C: No you've said, "when are you going to get married?" 


\section{M: Okay, Well I-}

C: And you want me to have 7 kids even though I specifically say no kids, I don't want them. I like to look at them from afar (sigh) you know me, I don't like kids.

M: I know, I'm okay with that.

C: No you're not.

We also saw this trend in other interviews, in which adolescents reported that their mothers endorsed the traditional narrative more than they suggested in the conversation. The mothers may have been positioning themselves towards a progressive narrative with which they would like to align, but are not quite able to rid themselves of the traditional narrative, particularly as it relates to romantic commitment and having children. This is consistent with the lack of gender differences in expectations compared to experiences in Study 1a. Those issues of romance and children also seem to be the least negotiable (consistent with the reflections in Study 1b, as well as the ratings for romance in Study 1a), perhaps in part because the mothers think this will bring their children happiness, and parents want their children to be happy. Such events may also bring the parents happiness as they assume the culturally-valued in-law and grandparent roles.

In sum, we saw either a neglect of the traditional narrative in favor of the equality narrative, or the equality narrative socialized in paradox. We argue that both of these strategies can work to maintain the traditional narrative. The latter creates confusion and uncertainty. And the former ignores the realities of structural inequalities and cultural expectations that still exist. We see this as analogous to data showing that not talking about race is associated with more racism (e.g., Hughes, Bigler, \& Levy, 2007; see also Tatum, 1994) - not acknowledging these systemic issues may reflect an implicit endorsement of them.

\section{General Discussion}


Using a mixed methods design, triangulating across samples and methods, we saw that the traditional gendered biographical narrative still holds a strong grip in the lives of emerging adults and adolescents and their parents, particularly for issues related to family and romance. Even as a newer narrative of gender equality is visible, it comes with paradoxes that pose challenges for personal identity development. We also saw that deviating or conforming is not necessarily a binary option, but something that is actively negotiated (Rogers \& Way, 2018). We focus our general discussion on the implications of these results regarding socialization and identity development for understanding cultural change.

Though there are far more similarities than differences in biographical expectations for men and women, the points of divergence are meaningful -childbearing/rearing, work, romance - which seek to reify the traditional narrative. However, in terms of personal experiences, most of our participants deviated, which suggests cultural movement. Thus, the more people do not conform, the more possibility of changing the master narrative. However, since the majority still think these experiences are deviations structural changes that facilitate changes in personal and master narratives (e.g., parental leave) may be important. This is a claim of this framework that responsibility for changing master narratives is both a personal and a structural issue (McLean \& Syed, 2015).

Yet changing the master narrative may not only rely on the mass movement towards an alternative narrative, but also on the coherence of that alternative narrative to facilitate individual identity development. The traditional narrative is clear - people are easily able to describe the expectations of it, they know when they have violated it, and can understand their identities accordingly. But the equality narrative does not prescribe events - there is no template for individuals as they try to understand their experiences or future pathways. That may appear to 
be a liberation from the traditional gendered constraints (and inequalities) of cultural prescription, but master narratives have a utility - they help people to construct an identity. Without specific cultural expectations, the trajectory of identity development is amorphous, and the traditional narrative may maintain its hold. Indeed, we see at least two ways in which endorsement of the traditional and egalitarian narratives may sustain systems of inequality via identity and socialization processes.

First, the personal endorsement of the traditional narrative is a clear mechanism of narrative maintenance, but so may endorsement of the equality narrative. Although the equality narrative may allow a relief from the burden of perceiving constraint, it is also a relief from the burden of addressing inequality. For example, a man who endorses the equality narrative may not acknowledge a gender-based wage gap thus exempting him from working to change the culture that supports gender inequality (see also Weststrate \& McLean, 2010 for a discussion of similar issues regarding sexuality, and Rogers \& Way, 2016 for similar arguments regarding stereotype maintenance). The equality expressed may also be addressed explicitly because it is more novel, and this explicit communication could be interpreted as evidence that there is a new narrative. However, the qualitative data reveal the importance of implicit socialization that may be an obstacle to the equality narrative taking hold, and for individuals who are trying to understand their own experiences and future possibilities.

Second, the mothers who did not explicitly address equality may be implicitly endorsing the traditional narrative. For example, we saw some mothers emphasizing 'choice' as reflecting the equality narrative, even if the choice is the traditional path. But that 'choice' gives visibility to the traditional narrative and all of the structural constraints and inequalities it holds. This emphasis on choice also represents a broad cultural value in America of choice and meritocracy. 
Here it is narrativized by suggesting that the events in one's biography can be agentically chosen, selected rather than dictated by a cultural template (McLean \& Syed, 2015). Indeed, until these systemic issues are addressed, we cannot know how much agency one has to 'choose' the traditional pathway.

\section{Limitations and Future Directions}

Our main limitation is that we examined gender decontextualized from other central features of self, notably ethnicity/race, and sexuality. This was beyond the scope of this paper, but clearly the understanding of master and alternative narratives necessitates thinking about the characteristics of the groups to which they do (or do not) apply. However, we do interpret these results from a lens of intersectionality, such that the relative privilege of this sample (largely straight, white, and educated) may dictate the contents of gender identity (e.g., work-family balance), which may be qualitatively distinct for other groups.

We also note that our prompt in Study 1 asked for narrative deviations. We did this because we have found this prompt useful in eliciting master narratives (e.g., McLean et al., 2017), and because asking for conformity can be challenging as individuals are not always aware

of their conformity. However, those interested in understanding more about alignment may want to develop different prompts not focused on deviation.

In terms of future directions, we are struck by the potential for mapping to other literature on parental socialization, particularly racial and ethnic socialization. These are clearly not the same topics, and there are developmental differences in attitudes about race and gender (e.g., Dunham, Baron, \& Banaji, 2015). However, distinguishing gender socialization in terms of interests or relational orientation, one sees parallels to ethnic or cultural socialization. Socializing around barriers to opportunity or sexual assault reveals parallels to racial 
socialization. Racial and ethnic socialization predict different aspects of functioning and development, and so too could these different aspects of gender socialization.

We were also limited in the analysis of adolescents and emerging adults, whom we chose to investigate because of the salience of the developmental task of identity construction. However, engaging in similar tasks with individuals of different generational cohorts may speak to how cultural stories and norms have shifted over time, and perhaps how stories are shared from generation to generation, elucidating how master narratives develop via the process of such sharing.

In sum, our analysis is framed within recent calls for attention to structural components of human functioning in the field of psychology (McLean \& Syed, 2015; Stewart \& Zucker, 2016) and issues of equity and justice within developmental psychology (Killen, Rutland, \& Yip, 2016; Rogers \& Way, 2018). We emphasize the importance of understanding the individual psychological processes so central to development, as embedded within socio-cultural systems that include power and hierarchy. Such a lens broadens the understanding of development to necessarily include the cultural context in which individuals develop. 


\section{References}

Arnett, J. (2017). Life stage concepts across history and cultures: Proposal for a new field on indigenous life stages. Human Development, 59(5), 290-316. doi:10.1159/000453627.

Balistreri, E., Busch-Rossnagel, N. A., \& Geisinger, K. F. (1995). Development and preliminary validation of the Ego Identity Process Questionnaire. Journal of Adolescence, 18(2), 179192. doi:/10.1006/jado.1995.1012.

Bamberg, M. (2004). Considering counter narratives. In M. Bamberg \& M. Andrews (Eds.), Considering counter-narratives: Narrating, resisting, making sense (pp. 351-372). Amersterdam/Philadelphia: John Benjamins Publishing Company.

Berntsen, D., \& Rubin, D. C. (2004). Cultural life scripts structure recall from autobiographical memory. Memory \& Cognition, 32(3), 427-442. doi:10.3758/bf03195836

Bronfenbrenner, U. (1979). The ecology of human development. Harvard university press.

Dunham, Y., Baron, A. S., \& Banaji, M. R. (2016). The development of implicit gender attitudes. Developmental Science, 19(5), 781-789. doi:10.1111/desc.12321.

Egan, S. K., \& Perry, D. G. (2001). Gender identity: A multidimensional analysis with implications for psychosocial adjustment. Developmental Psychology, 37(4), 451-463. doi:10.1037/0012-1649.37.4.451.

Erikson, E. H. (1968). Identity, youth, and crisis. New York: W.W. Norton.

Fivush, R., \& Buckner, J. P. (2003). Creating gender and identity through autobiographical narratives. In R. Fivush, C. A. Haden, R. Fivush, C. A. Haden (Eds.), Autobiographical memory and the construction of a narrative self: Developmental and cultural perspectives (pp. 149-167). Mahwah, NJ, US: Lawrence Erlbaum Associates Publishers. 
Gelman, S. A., Taylor, M. G., Nguyen, S. P., Leaper, C., \& Bigler, R. S. (2004). Mother-child conversations about gender: Understanding the acquisition of essentialist beliefs. Monographs of the Society for Research in Child Development, i-142.

Gilligan, C. (1982). In a different voice. Harvard University Press.

Habermas, T. (2007). How to tell a life: The development of the cultural concept of biography across the lifespan. Journal of Cognition, 8, 1-31. doi: 10.1080/15248370709336991.

Hammack, P. L. (2008). Narrative and the cultural psychology of identity. Personality and Social Psychology Review, 12(3), 222-247. doi:10.1177/1088868308316892.

Heckhausen, J., Wrosch, C., \& Fleeson, W. (2001). Developmental regulation before and after a developmental deadline: The sample case of" biological clock" for childbearing. Psychology and Aging, 16(3), 400. doi:10.1037/0882-7974.16.3.400.

Helson, R., Mitchell, V., \& Moane, G. (1984). Personality and patterns of adherence and nonadherence to the social clock. Journal of Personality and Social Psychology, 46(5), 1079. doi:10.1037//0022-3514.46.5.1079.

Hughes, D., \& Johnson, D. (2001). Correlates in children's experiences of parents' racial socialization behaviors. Journal of Marriage and Family, 63(4), 981-995. doi:10.1111/j.1741-3737.2001.00981.x.

Hughes, J. M., Bigler, R. S., \& Levy, S. R. (2007). Consequences of learning about historical racism among European American and African American children. Child Development, 78, 1689-1705. http://dx.doi.org/10.1111/j.1467-

\subsubsection{6.x.}


Killen, M., Rutland, A., \& Yip, T. (2016). Equity and justice in developmental science: Discrimination, social exclusion, and intergroup attitudes. Child Development, 87(5), 1317-1336. doi:10.1111/cdev.12593.

Korobov, N., \& Bamberg, M. (2004). Positioning a 'mature' self in interactive practices: How adolescent males negotiate 'physical attraction' in group talk. British Journal of Developmental Psychology, 22(4), 471-492. doi:10.1348/0261510042378281.

Lindsey, L. L. (2015). Gender roles: A sociological perspective. New York, NY: Routledge.

McLean, K. C., Lilgendahl, J. P., Fordham, C., Alpert, L., Marsden, E., \& Szymanowski, K., \& McAdams, D. P. (2017a). Master identity development in cultural context: The role of deviating from master narratives. Journal of Personality, 65, 1-21. doi:10.1111/jopy.12341

McLean, K. C., Shucard, H., \& Syed, M. (2017b). Applying the master narrative framework to gender identity in emerging adulthood: Emerging Adulthood, 5, 93-105. doi: $10.1177 / 2167696816656254$

McLean, K. C. \& Syed, M. (2015). Personal, master, and alternative narratives: An integrative framework for understanding identity development in context. Human Development. doi: $10.1159 / 000445817$.

Meeussen, L., Veldman, J., \& Van Laar, C. (2016). Combining gender, work, and family identities: the cross-over and spill-over of gender norms into young adults' work and family aspirations. Frontiers in Psychology, 7, 1781. doi:10.3389/fpsyg.2016.01781.

Neugarten, B. L., Moore, J. W., \& Lowe, J. C. (1965). Age norms, age constraints, and adult socialization. American Journal of Sociology, 70(6), 710-717. doi:10.1086/223965 
Pasupathi, M., Mansour, E., \& Brubaker, J. R. (2007). Developing a life story: Constructing relations between self and experience in autobiographical narratives. Human Development, 50(2-3), 85-110. doi:10.1159/000100939.

Risman, B. J. (2004). Gender as a social structure: Theory wrestling with activism. Gender \& Society, 18(4), 429-450. doi:10.1177/0891243204265349.

Rogers, L. O., \& Meltzoff, A. N. (2017). Is gender more important and meaningful than race? An analysis of racial and gender identity among Black, White, and mixed-race children. Cultural Diversity and Ethnic Minority Psychology, 23(3), 323. doi:10.1037/cdp0000125

Rogers, L. O., \& Way, N. (2016). 'I have goals to prove all those people wrong and not fit into any one of those boxes': Paths of resistance to stereotypes among Black adolescent males. Journal of Adolescent Research, 31(3), 263-298. doi:10.1177/0743558415600071.

Rogers, L. O., \& Way, N. (2018). Reimagining social and emotional development: Accommodation and resistance to dominant ideologies in the identities and friendships of boys of color. Human Development, 1-21. doi:10.1159/000493378.

Ruble, D. N., Martin, C. L., \& Berenbaum, S. A. (2006). Gender Development. In N. Eisenberg, W. Damon, \& R. M. Lerner (Eds.), Handbook of child psychology: Social, emotional, and personality development (pp. 858-932). Hoboken, NJ, US: John Wiley \& Sons Inc.

Rubin, D. C., \& Berntsen, D. (2003). Life scripts help to maintain autobiographical memories of highly positive, but not highly negative, events. Memory \& Cognition, 31(1), 1-14. doi:10.3758/bf03196077.

Stewart, A. J., \& Zucker, A. N. (2016). "Who is tossing whom into the current? A social justice perspective on gender and well-being. In P. L. Hammack (Ed.), The Oxford Handbook of Social Psychology and Social Justice. doi:10.1093/oxfordhb/9780199938735.013.19. 
Syed, M., \& McLean, K. C. (2016). Understanding identity integration: Theoretical, methodological, and applied issues. Journal of Adolescence, 47, 109-118. doi:10.1016/j.adolescence.2015.09.005.

Syed, M., \& Nelson, S. C. (2015). Guidelines for establishing reliability when coding narrative data. Emerging Adulthood, 3(6), 375-387. doi:10.1177/2167696815587648.

Tatum, B. (1994). Teaching white students about racism: The search for white allies and the

restoration of hope. Teachers College Record, 95, 462-476.

Tenenbaum, H. R., \& Leaper, C. (2002). Are parents' gender schemas related to their children's gender-related cognitions? A meta-analysis. Developmental Psychology, 38(4), 615. doi:10.1037//0012-1649.38.4.615.

Thorne, A., \& McLean, K. C. (2003). Telling traumatic events in adolescence: A study of master narrative positioning. In R. Fivush \& C. Haden (Eds.), Connecting culture and memory: The development of an autobiographical self, pp. 169-185. Mahwah, NJ: Erlbaum.

Toolis, E.E., \& Hammack, P.L. (2015). The lived experience of homeless youth: A narrative approach. Qualitative Psychology, 2(1), 50-68.

Weststrate, N. M., \& McLean, K. C. (2010). The rise and fall of gay: A cultural-historical approach to gay identity development. Memory, 18(2), 225-240. doi:10.1080/09658210903153923.

Zaman, W., \& Fivush, R. (2011). When my mom was a little girl...: Gender differences in adolescents' intergenerational and personal stories. Journal of Research on Adolescence, 21(3), 703-716. doi:10.1111/j.1532-7795.2010.00709.x. 
Gender Identity and Master Narratives 35 
Table 1

Means (SDs) and Frequencies (\%) for Main Variables

\begin{tabular}{llll}
\hline Variable (Range) & Sample & Male & Female \\
\hline Age $(19-29)$ & $20.39(2.89)$ & $20.15(2.64)$ & $20.63(2.89)$ \\
Gender & 404 & $200(49)$ & $204(51)$ \\
Alternative Narrative $(1-4)$ & $2.54(1.07)$ & $2.47(1.06)$ & $2.63(1.07)$ \\
$\begin{array}{l}\text { Ego Identity Process Questionnaire } \\
\text { Exploration (1-7) }\end{array}$ & $4.72(.72)$ & $4.67(.73)$ & $4.76(.71)$ \\
$\begin{array}{l}\text { Self-event Connections (presence) } \\
\text { (1- }\end{array}$ & $74(18)$ & $46(23)$ & $28(14)$ \\
\hline
\end{tabular}


Table 2

Descriptives for Participant-generated Biographical Master Narrative Events

\begin{tabular}{|c|c|c|c|c|c|}
\hline \multirow[t]{2}{*}{ Event Category } & \multicolumn{3}{|c|}{ Frequency $(\%)$} & \multirow[t]{2}{*}{ Kappa } & \multirow[t]{2}{*}{$\%$ Agreement } \\
\hline & Male & Female & Sample & & \\
\hline Graduating High School & $140(75)$ & $140(77)$ & $280(75)$ & 1.00 & 100.00 \\
\hline Graduating University & $140(75)$ & $153(85)$ & $293(79)$ & 0.84 & 94.00 \\
\hline Having a Child & $152(81)$ & $165(91)$ & $317(85)$ & 0.44 & 88.00 \\
\hline Choosing a Career & $137(73)$ & $142(79)$ & $279(75)$ & 0.64 & 85.00 \\
\hline Caring for Parents in Old Age & $1(.5)$ & $4(2)$ & $5(1)$ & 0.00 & 100.00 \\
\hline Purchase a Home & $39(21)$ & $30(17)$ & $69(19)$ & 1.00 & 100.00 \\
\hline Travel to Another Country & $17(9)$ & $23(13)$ & $40(11)$ & 0.79 & 97.00 \\
\hline Get Married & $158(84)$ & $165(91)$ & $323(87)$ & 0.63 & 94.00 \\
\hline Devote Energy to Career Adv. & $11(6)$ & $16(9)$ & $27(7)$ & 0.62 & 91.00 \\
\hline Devote Energy to Childrearing & $14(7)$ & $41(23)$ & $55(15)$ & 0.84 & 94.00 \\
\hline Fall in Love & $22(12)$ & $26(14)$ & $48(13)$ & 0.87 & 94.00 \\
\hline Retire & $90(48)$ & $75(41)$ & $165(44)$ & 0.76 & 88.00 \\
\hline Have a Grandchild & $25(13)$ & $43(24)$ & $68(18)$ & 0.92 & 97.00 \\
\hline Leave Home & $12(6)$ & $13(7)$ & $25(7)$ & 1.00 & 100.00 \\
\hline
\end{tabular}


Table 3

Means (Standard Deviations) for Importance of Life Course Events

\begin{tabular}{|c|c|c|c|c|c|c|}
\hline & $\begin{array}{l}\text { Sample } \\
M(S D)\end{array}$ & $\begin{array}{c}\text { Male } \\
M(S D)\end{array}$ & $\begin{array}{l}\text { Female } \\
M(S D)\end{array}$ & $t$ & $p$ & $\begin{array}{c}\text { Cohen's } \\
d\end{array}$ \\
\hline Graduate High School & $4.77(0.57)$ & $4.72(0.67)$ & $4.83(0.44)$ & -1.918 & .056 & .19 \\
\hline Graduate University & $4.41(0.73)$ & $4.36(0.72)$ & $4.47(0.73)$ & -1.499 & .135 & .15 \\
\hline Having a Child & $3.80(1.16)$ & $3.77(1.11)$ & $3.83(1.21)$ & -0.499 & .618 & .05 \\
\hline Choosing a Career & $4.56(0.73)$ & $4.72(0.61)$ & $4.41(0.81)$ & 4.371 & $<.001$ & .43 \\
\hline Care for Aging Parents & $4.11(0.91)$ & $4.23(0.82)$ & $3.99(0.98)$ & 2.681 & .008 & .26 \\
\hline Purchase a Home & $4.00(0.96)$ & $4.13(0.91)$ & $3.86(1.00)$ & 2.878 & .004 & .28 \\
\hline Travel Abroad & $3.45(1.12)$ & $3.46(1.19)$ & $3.44(1.25)$ & 0.197 & .844 & .02 \\
\hline Get Married & $3.94(1.19)$ & $3.94(1.15)$ & $3.94(1.23)$ & -0.008 & .994 & .00 \\
\hline Career Advancement & $3.91(1.09)$ & $4.29(0.83)$ & $3.78(0.96)$ & 5.631 & $<.001$ & .56 \\
\hline Energy to Childrearing & $3.91(1.09)$ & $3.92(1.00)$ & $3.89(1.18)$ & 0.308 & .758 & .03 \\
\hline Fall in Love & $4.28(0.96)$ & $4.31(0.91)$ & $4.26(1.00)$ & 0.516 & .606 & .05 \\
\hline Retire & $4.16(0.99)$ & $4.18(1.02)$ & $4.15(0.96)$ & 0.277 & .782 & .03 \\
\hline Have a Grandchild & $3.65(1.15)$ & $3.65(1.12)$ & $3.64(1.19)$ & 0.127 & .899 & .01 \\
\hline Leave Home & $4.36(0.92)$ & $4.36(0.99)$ & $4.35(.86)$ & 0.112 & .911 & .01 \\
\hline
\end{tabular}


Table 4

Frequencies (Percent) for Deviation and Conformity

\begin{tabular}{|c|c|c|c|c|c|c|}
\hline & $\begin{array}{l}\text { Male } \\
n(\%)\end{array}$ & $\begin{array}{l}\text { Female } \\
n(\%)\end{array}$ & Total $\mathrm{N}$ & $\begin{array}{c}\text { ASR } \\
\text { (absolute } \\
\text { value) }\end{array}$ & Kappa & $\begin{array}{c}\% \\
\text { Agreement }\end{array}$ \\
\hline Norms of Masc. \& Fem. & $50(25)$ & $33(16)$ & 83 & 2.2 & 1.00 & $100 \%$ \\
\hline Sexuality & $15(8)$ & $6(3)$ & 21 & 2.1 & 1.00 & $100 \%$ \\
\hline Gender Role Beliefs & $7(4)$ & $8(4)$ & 15 & 0.2 & 0.51 & $92 \%$ \\
\hline Timing/Omission of Events & $13(7)$ & $12(6)$ & 25 & 0.3 & 0.72 & $92 \%$ \\
\hline Unexpected Events & 37 (19) & $35(17)$ & 72 & 0.4 & 0.84 & $95 \%$ \\
\hline Gendered Life Course Event & $13(7)$ & $46(23)$ & 59 & 4.4 & 0.42 & $92 \%$ \\
\hline Other & $7(4)$ & $9(4)$ & 16 & 0.5 & 0.64 & $95 \%$ \\
\hline Non-specific Conformity & $22(11)$ & $17(8)$ & 39 & 0.9 & 0.70 & $95 \%$ \\
\hline Traditional Narr Conformity & $23(12)$ & $15(7)$ & 38 & 1.5 & 1.00 & $100 \%$ \\
\hline $\begin{array}{l}\text { Equality Narrative } \\
\text { Conformity }\end{array}$ & $1(<1)$ & $11(5)$ & 12 & 2.9 & 0.49 & $97 \%$ \\
\hline
\end{tabular}

